\title{
Early introduction of fish decreases the risk of eczema in infants
}

\author{
B Alm, ${ }^{1} \mathrm{~N}$ Åberg, ${ }^{1}$ L Erdes, ${ }^{3}$ P Möllborg, ${ }^{2}$ R Pettersson, ${ }^{4}$ S G Norvenius, ${ }^{1}$ E Goksör, \\ G Wennergren'
}

${ }^{1}$ Department of Paediatrics,

University of Gothenburg, Queen Silvia Children's Hospital,

Gothenburg, Sweden; ${ }^{2}$ Central Infant Welfare Unit, Uddevalla Hospital, Uddevalla, Sweden;

${ }^{3}$ Paediatric Outpatient Clinic,

Skene Hospital, Skene, Sweden;

${ }^{4}$ Department of Paediatrics,

Skaraborg Hospital, Skövde,

Sweden

Correspondence to:

Bernt Alm, Department of

Paediatrics, University of

Gothenburg, Queen Silvia

Children's Hospital, SE-416 85

Gothenburg, Sweden;

bernt.alm@medfak.gu.se

Accepted 27 July 2008

Published Online First

25 September 2008

\section{ABSTRACT}

Background: Atopic eczema in infants has increased in western societies. Environmental factors and the introduction of food may affect the risk of eczema.

Aims: To investigate the prevalence of eczema among infants in western Sweden, describe patterns of food introduction and assess risk factors for eczema at 1 year of age.

Methods: Data were obtained from a prospective, longitudinal cohort study of infants born in western Sweden in 2003; 8176 families were randomly selected and, 6 months after the infant's birth, were invited to participate and received questionnaires. A second questionnaire was sent out when the infants were 12 months old. Both questionnaires were completed and medical birth register data were obtained for 4921 infants (60.2\% of the selected population).

Results: At 1 year of age, 20.9\% of the infants had previous or current eczema. Median age at onset was 4 months. In multivariable analysis, familial occurrence of eczema, especially in siblings (OR 1.87; 95\% confidence interval (CI) 1.50 to 2.33) or the mother (OR 1.54; $95 \% \mathrm{Cl}$ 1.30 to 1.84$)$, remained an independent risk factor. Introducing fish before 9 months of age (OR 0.76; $95 \% \mathrm{Cl}$ 0.62 to 0.94 ) and having a bird in the home (OR 0.35 ; $95 \% \mathrm{Cl} 0.17$ to 0.75 ) were beneficial.

Conclusions: One in five infants suffer from eczema during the first year of life. Familial eczema increased the risk, while early fish introduction and bird keeping decreased it. Breast feeding and time of milk and egg introduction did not affect the risk.

Eczema in infants is a common health problem throughout the world, although the incidence varies. ${ }^{1}$ However, heredity is known to exert a major influence, ${ }^{2}$ and food and the period of food introduction may have an effect on age at onset and the severity of the disease.

There has been a substantial increase in the prevalence of allergic diseases in recent decades, ${ }^{34}$ but the reasons for this are still unknown despite intensive research. The low prevalence of allergy in Eastern Europe was thought to be due to a difference in intestinal flora. ${ }^{5}$ In addition, data from experimental animal studies suggest that early contact with allergens might provide protection from subsequent sensitisation, ${ }^{6}$ which is also supported by epidemiological findings. ${ }^{7}$ However, other studies report different results. ${ }^{8}$

There is consensus that parental tobacco smoking plays an important role in the occurrence of early wheezing, but the influence on eczema is disputed. ${ }^{9-11}$ Dairy products, ${ }^{12}$ omega-3 fatty acids ${ }^{13}$ and a diet containing lactobacilli ${ }^{14}$ have been

\section{What is already known on this topic}

Eczema is common in infants.

- Heredity is a strong risk factor.

\section{What this study adds}

- The introduction of fish before 9 months of age reduces the risk of eczema.

- Breast feeding does not provide protection from eczema during the first year of life.

suggested to be protective factors against the development of atopy.

The aims of this study were to investigate the current prevalence of eczema among infants in western Sweden, to describe current patterns of food introduction and to assess the risk factors for eczema at 1 year of age.

\section{METHODS}

"Infants of Western Sweden" is an ongoing study in western Sweden. The region has 1.5 million inhabitants (one sixth of the Swedish population) and consists of urban, rural and coastal areas. Gothenburg, with 500000 inhabitants, is the largest city.

From the total birth cohort of 16682 infants born in the region in 2003, 8176 families (50\%) were randomly selected. ${ }^{15}$ When the infant was 6 months of age, the family was sent an invitation and a questionnaire (Q1) which sought detailed information on the family, environment, perinatal history, tobacco, breast feeding, food introduction and diseases in the first year, with special reference to allergic diseases. Families willing to participate returned written informed consent together with the questionnaire. These families were then sent a second questionnaire (Q2) when the child was 12 months of age. Q1 was sent out to 8176 families and completed by 5605 , giving a response rate of $68.5 \%$. Of these 5605 families, 4941 also completed Q2 (88.2\% of those who answered Q1). Medical birth register data were available for 4921 (99.6\%) of these 4941 (60.2\% of the originally selected population). Details relating to the questionnaires have previously been published. ${ }^{16}{ }^{17}$ online under the BMJ Journals unlocked scheme, see http:// adc.bmj.com/info/unlocked.dtl 
The question on eczema was: "Has your child had eczema? $(y / n)$ ", while that on food allergy was: "Has your child a diagnosis of food allergy from a doctor? $(y / n)$ ". Food frequency data were collected at 6 and 12 months.

In the statistical analysis of eczema, $2 \times 2$ tables with the $\chi^{2}$ test and binary logistic regression were used and risks were estimated using odds ratios (OR) with 95\% confidence intervals (CI). Factors that were significant with a $p$ value of $<0.01$ in the univariable analysis were then analysed in a multivariable model. Secondary (disease-associated) variables were excluded and further adjustment was carried out for "atopic reasons" for not having furry animals in the home (manifest allergy or fear of allergy), plus cow's milk allergy. The SPSS statistical package v 15.0 was used for calculations. ${ }^{18}$

The study was approved by the ethics committee at the University of Gothenburg.

Table 1 Reported prevalence of eczema, diagnosed food allergy, pet keeping and dietary factors in infants in western Sweden in 2004-2005: the Infants of Western Sweden Study

\begin{tabular}{|c|c|}
\hline & n (\%) \\
\hline \multicolumn{2}{|l|}{ Eczema $(n=4953)$} \\
\hline At 6 months & $692(13.9)$ \\
\hline At 12 months & $1033(20.9)$ \\
\hline \multicolumn{2}{|l|}{ Food allergy $(n=4944)$} \\
\hline Any food allergy & $241(4.9)$ \\
\hline Cow's milk & $194(3.9)$ \\
\hline Eggs & $126(2.5)$ \\
\hline Fruit or vegetables & $41(0.83)$ \\
\hline Cereals & $18(0.36)$ \\
\hline Fish & $14(0.28)$ \\
\hline Soy protein & $12(0.24)$ \\
\hline Peanuts & $10(0.20)$ \\
\hline Peas & $9(0.18)$ \\
\hline Nuts or almonds & $8(0.16)$ \\
\hline \multicolumn{2}{|l|}{ Pets in the home $(n=4987)$} \\
\hline Cat & $1076(21.6)$ \\
\hline Dog & $729(14.6)$ \\
\hline Rodent & $162(3.2)$ \\
\hline Bird & $113(2.3)$ \\
\hline \multicolumn{2}{|c|}{ Main type of fat on bread $(n=4893)$} \\
\hline Butter & $3488(71.3)$ \\
\hline Margarine & $1164(23.8)$ \\
\hline Nil & $241(4.9)$ \\
\hline \multicolumn{2}{|c|}{$\begin{array}{l}\text { Frequency of lactic acid (yoghurt, fermented vegetables, } \\
\text { etc) in the diet }(n=4929)\end{array}$} \\
\hline 3+ Times/week & $2497(50.7)$ \\
\hline 1-3 Times/week & $1439(29.2)$ \\
\hline 1-3 Times/month & $531(10.8)$ \\
\hline Occasionally & $161(3.3)$ \\
\hline Never & $301(6.1)$ \\
\hline \multicolumn{2}{|c|}{ Frequency of fish consumption $(n=4953)$} \\
\hline 3+ Times a week & $250(5.0)$ \\
\hline 1-3 Times a week & $2995(60.5)$ \\
\hline 1-3 Times a month & $1296(26.2)$ \\
\hline A few times a year & $217(4.4)$ \\
\hline Never & $195(3.9)$ \\
\hline \multicolumn{2}{|c|}{ Type of fish usually consumed ( $\mathrm{n}=4473$ ) } \\
\hline Lean fish (cod, haddock) & $3516(78.6)$ \\
\hline Salmon & $772(17.3)$ \\
\hline Flatfish & $140(3.1)$ \\
\hline Mackerel or herring & $45(1.0)$ \\
\hline
\end{tabular}

\section{RESULTS}

\section{Eczema}

At 6 months of age, $13.9 \%$ of families said that their infant had previous or current eczema, while the corresponding figure at 12 months was $20.9 \%$ (table 1 ). The median age at onset was 4 months (mean age 5.4 months).

\section{Food allergy}

Food allergy had been diagnosed by a physician in $4.9 \%$ of the study population (table 1).

\section{Furry pets}

Many families had furry pets. The most common was a cat $(21.6 \%)$, followed by a dog $(14.6 \%)$ and rodents $(3.2 \%)$. The keeping of pets was more common in rural than in urban areas. For example, dogs were kept by $8.4 \%$ of the households in the city of Gothenburg, while the figures were $25.8 \%$ and $20.7 \%$ in the counties of Dalsland and Skaraborg, respectively.

\section{Breast feeding and food introduction}

Breast feeding and timing of the introduction of cow's milk protein, cereals and solids are described in figs 1 and 2 . At the age of 16 weeks, more than $80 \%$ of the infants were breast fed, while one third were exclusively breast fed (no cow's milk protein introduced) (fig 1). At the age of 6 months, two thirds were still breast fed and 10\% were exclusively breast fed. At about 30 weeks, $50 \%$ of the infants had been weaned (fig 1).

The median age for the introduction of cow's milk protein was 9 weeks, compared with 18 weeks for the introduction of solids and 22 weeks for cereals (fig 2).

Fish was introduced at a median age of 7 months and eggs at a median age of 9 months (fig 2).

Butterfat was used on bread by $71.3 \%$ of the families at 12 months, while $50.7 \%$ consumed fermented dairy products (table 1) more than three times a week. When they ate fish, $18.3 \%$ mainly consumed fat fish such as salmon.

\section{Risk factors for eczema at 1 year Univariable analysis}

The variables significant at $p<0.01$ are presented in table 2 . The non-significant variables with a $p$ value between 0.01 and 0.05 as well as those with a $p$ value $\geqslant 0.05$ are listed in the footnote.

\section{Multivariable analysis}

In the multivariable analysis, significant risk factors were maternal eczema, a sibling with eczema, a bird in the home, the introduction of fish before 9 months of age and cow's milk allergy (table 3).

Since breast feeding and smoking were non-significant $(p>0.01)$ in the univariable analysis they were not included in the final multivariable model. However, since the effects of breast feeding and smoking on allergic disease are debated, we also carried out an analysis including these factors in the model. This confirmed that they were not statistically significant risk factors.

\section{DISCUSSION}

This study shows that one in five infants have eczema during the first year of life and, as expected, there is a strong association with a family history of eczema. Furthermore, we found beneficial effects from introducing fish before 9 months of age, while short duration of breast feeding, keeping furry pets 


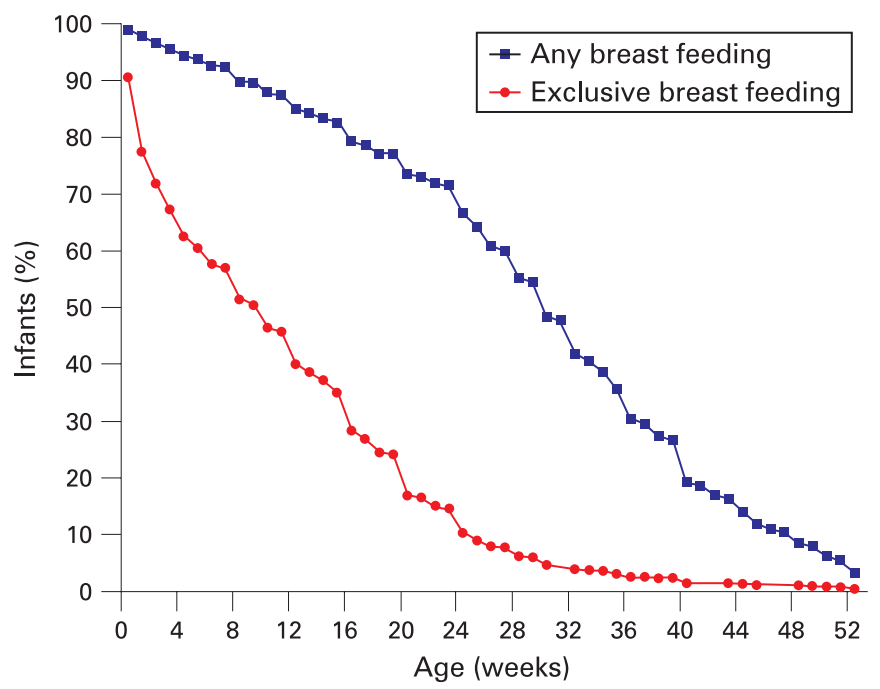

Figure 1 Prevalence of exclusive breast feeding and any breast feeding during the first year of life in western Sweden, 2003-2004.

or the age at which milk or eggs were introduced did not affect the risk.

The KOALA Birth Cohort Study ${ }^{19}$ found a prevalence of eczema of $22.2 \%$ at 1 year. In the BAMSE study, the prevalence of eczema was $25.1 \%$ ever before the age of $2 .{ }^{20}$ Our study confirms the high prevalence of eczema during the first year of life, with a cumulative prevalence of $13.9 \%$ at 6 months and $20.9 \%$ at 12 months of age.

The prevalence of eczema was estimated using questionnaires sent to the parents, with questions on whether the infant had previous or current eczema at 1 year of age and did not require a doctor's diagnosis. This may lead to uncertainty about the exact prevalence, but as we found a prevalence similar to those in other cohort studies, we believe that the results are valid.

To further evaluate the validity of our study material, we have compared the prevalence of smoking during pregnancy in our study $(9.5 \%)$ with recent statistics from the National Swedish Board of Health and Welfare which show that $10 \%$ of all pregnant women in western Sweden and in Sweden as a whole smoked in 2003. ${ }^{21}$ Since smoking is associated with several disadvantageous factors, we believe that the data from western Sweden are representative of the population.

The possibility of recall bias is always a limitation in questionnaire studies. However, as food data were collected at 6 and 12 months in this study, we do not think that recall bias is a major problem as the time intervals are relatively short.

Compared with data from Stockholm, ${ }^{22}$ more homes in western Sweden seem to have furry pets $(15.4 \%$ vs $20 \%$, respectively). This is probably because the BAMSE study recruited infants from central Stockholm, while our infants were from both urban and rural areas. In the western Sweden study, we found a higher prevalence of furry pets in rural areas.

There is consensus that sensitised children and children with symptoms of allergic disease should not have contact with furry pets. ${ }^{23}$ On the other hand, opinions differ as to whether furry pets in the local environment of a young child can act as a protective factor and help tolerance to develop, ${ }^{7} 910$ or whether animals are risk factors for the development of allergy in children in high-risk families. In our study, the initial protective effect of keeping a dog disappeared when adjusting for "atopic reasons" (manifest allergy or fear of allergy) for not keeping an animal. The protective effect of having a bird in the home may

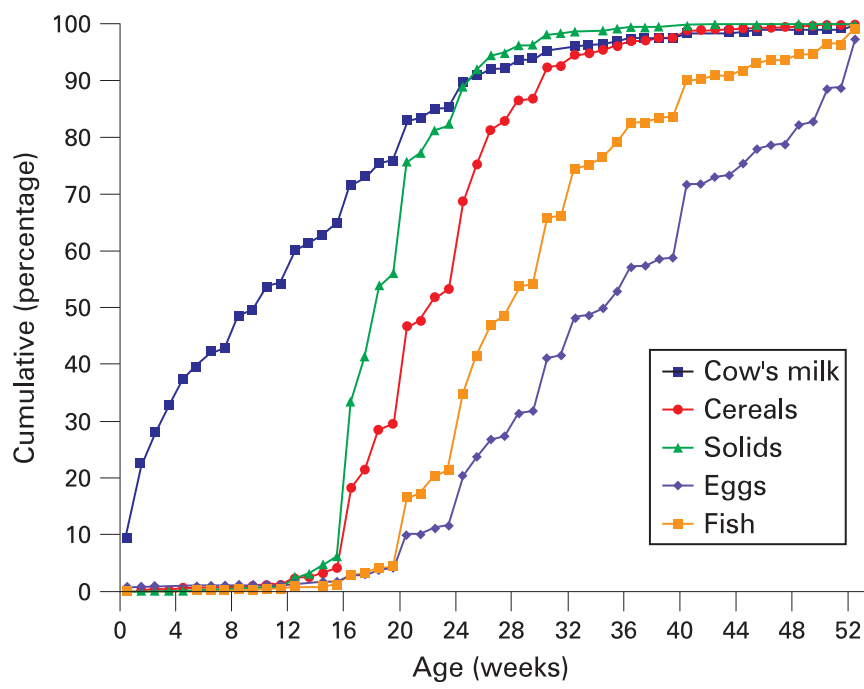

Figure 2 Food habits among infants: introduction of cow's milk protein, cereals, solids, eggs and fish in western Sweden, 2003-2004.

be due to reverse causation if non-atopic families keep more birds. However, some studies suggest that contact with feathers might prevent atopic disease. ${ }^{24-26}$ Since birds almost always are kept inside providing continuous indoor exposure, it may be that birds promote exposure to endotoxin. This might explain why we found a protective effect of bird keeping.

Previous primary preventive advice in Sweden recommended the delayed introduction of eggs and fish to infants with strong allergic heredity. Although this advice was abandoned in the autumn of 2002 because supportive evidence was lacking, ${ }^{23}$ we found that many parents waited to introduce eggs and fish. The results of our study show that outdated primary preventive advice which lacks evidence tends to be still followed by the general population. At the time of the study, allergy prevention advice placed no restrictions on the consumption of eggs or fish either in families at risk or in the rest of the population.

The results suggest that advice previously given at infant welfare clinics concerning the introduction of small portions of cereals and solids at 4 months of age is being followed, while cow's milk-based formulas and weaning foods are introduced earlier by many parents. The WHO code advocating exclusive breast feeding up to 6 months of age has been recommended in Sweden since 2001. The early steep rise in the curve showing the introduction of cow's milk (fig 2) could be explained by the parents (truthfully) counting every small helping of formula, for example during the neonatal period before the firm establishment of breast feeding.

In our study, the strongest risk factor for eczema was a family history of eczema and maternal eczema in particular. Our finding that a family history of eczema is a stronger risk factor than a family history of other atopic diseases is compatible with, for example, the ALSPAC study, where parental eczema was regarded as a better marker than parental asthma or hay fever. ${ }^{27}$ In fact, a Danish twin study found that genes accounted for $82 \%$ of individual susceptibility, while non-shared environmental factors accounted for $18 \%{ }^{28}$ Recently, it has been demonstrated that loss-of-function mutations in the filaggrin gene predispose to eczema. Filaggrin is a key protein of the epidermis that has an important role in the formation of the skin barrier. Loss of filaggrin function seems to play a role both in the pathogenesis of eczema and the subsequent progression of atopy. ${ }^{29} 30$ 
Table 2 Prevalence of significant $(p<0.01)$ risk factors for eczema at 1 year of age in the univariable analysis: the Infants of Western Sweden Study

\begin{tabular}{|c|c|c|c|c|}
\hline \multirow[b]{2}{*}{ Risk factor } & \multirow{2}{*}{$\begin{array}{l}\text { Eczema } \\
\text { n }(\%)\end{array}$} & \multirow{2}{*}{$\begin{array}{l}\text { No eczema } \\
\text { n (\%) }\end{array}$} & \multirow[b]{2}{*}{ OR $(95 \%$ CI) } & \multirow[b]{2}{*}{ p Value } \\
\hline & & & & \\
\hline Paternal asthma & $108(10.5)$ & $280(7.2)$ & $1.51(1.20$ to 1.91$)$ & 0.001 \\
\hline Maternal rhinoconjunctivitis & $320(31.3)$ & $833(21.5)$ & $1.66(1.42$ to 1.93$)$ & $<0.001$ \\
\hline Paternal rhinoconjunctivitis & $287(28.0)$ & $876(22.6)$ & $1.33(1.14$ to 1.56$)$ & $<0.001$ \\
\hline Sibling with rhinoconjunctivitis & $68(6.6)$ & $179(4.6)$ & $1.47(1.10$ to 1.96$)$ & 0.009 \\
\hline Maternal eczema & $392(38.3)$ & $917(3.7)$ & 2.00 (1.73 to 2.31$)$ & $<0.001$ \\
\hline Paternal eczema & $214(20.9)$ & $569(14.7)$ & $1.53(1.29$ to 1.83$)$ & $<0.001$ \\
\hline Living in an urban area & $631(62.5)$ & $2134(56.0)$ & 1.31 (1.14 to 1.51$)$ & $<0.001$ \\
\hline Maternal medication during pregnancy & $328(32.2)$ & $1066(27.7)$ & $1.24(1.07$ to 1.44$)$ & 0.005 \\
\hline Light sleeper at 6 months & $321(31.3)$ & $1016(26.2)$ & $1.28(1.10$ to 1.49$)$ & 0.001 \\
\hline Troubled sleep at 6 months & $150(14.6)$ & $434(11.2)$ & $1.36(1.11$ to 1.66$)$ & 0.003 \\
\hline 3+ Awakenings per night & $215(21.8)$ & $657(17.7)$ & 1.30 (1.09 to 1.54$)$ & 0.003 \\
\hline Male gender & $574(56.1)$ & $1979(51.1)$ & $1.22(1.06$ to 1.40$)$ & 0.005 \\
\hline 3-5 Months & $194(21.3)$ & $750(20.9)$ & $0.7(0.6$ to 0.9$)$ & 0.003 \\
\hline 6-8 Months & $462(50.8)$ & $2142(59.6)$ & 0.6 (0.5 to 0.7$)$ & $<0.001$ \\
\hline 9-12 Months & $248(27.3)$ & $689(19.2)$ & 1 (Ref) & Ref \\
\hline Type of fat on bread & & & & 0.003 \\
\hline Dairy & $674(67.2)$ & $2794(72.3)$ & 1 (Ref) & Ref \\
\hline Margarine & $280(27.9)$ & $878(22.7)$ & $1.32(1.13$ to 1.55$)$ & 0.001 \\
\hline Nil & $49(4.9)$ & $191(4.9)$ & $1.06(0.77$ to 1.47$)$ & 0.71 \\
\hline Frequency of fish consumption & & & & $<0.001$ \\
\hline 3+ Times a week & $54(5.3)$ & $195(5.0)$ & 1 (Ref) & Ref \\
\hline 1-3 Times a week & $584(57.0)$ & $2400(61.6)$ & $0.88(0.64$ to 1.20$)$ & 0.42 \\
\hline $1-3$ Times a month & $247(24.1)$ & $1038(26.6)$ & $0.86(0.62$ to 1.20$)$ & 0.37 \\
\hline A few times a year & $57(5.6)$ & $156(4.0)$ & $1.32(0.86$ to 2.02$)$ & 0.20 \\
\hline Never & $125(12.3)$ & $174(4.5)$ & 2.87 (2.24 to 3.69$)$ & $<0.001$ \\
\hline Troubled sleep at 12 months & $203(19.7)$ & $611(15.6)$ & $1.32(1.11$ to 1.58$)$ & 0.002 \\
\hline
\end{tabular}

Variables with $\mathrm{p}$ between 0.01 and 0.05 were: maternal asthma, air pollution in neighbourhood, feeding difficulties in first week, breast feeding, maternal education, paternal education, light sleeper at 12 months.

Variables with $p \geqslant 0.05$ were: number of siblings, sibling with asthma, cohabitation, maternal and paternal employment, type of housing, dampness or mould in the house, access to a summer cottage, lifestyle (leisure activities), regular maternity check-ups, maternal alcohol consumption during or after pregnancy, low birth weight, preterm birth, admission to neonatal ward, neonatal antibiotics, early introduction of cow's milk (first week), temperament first week, weak sucking, vomiting, maternal and paternal smoking during pregnancy, maternal and paternal smoking after pregnancy, sleeping position, sleeping place, hours outdoors, sleeping indoors with outdoor clothes on, temperament at 6 months, colicky pains, appetite, dummy at 6 months, cohabitation, maternal return to work, moved house between 6 and 12 months, cat or rodent at home, age at introduction of cow's milk, gluten, solids or eggs, type of fat used in cooking, vegetarianism in family, AD vitamin supplementation, appetite, vaccinations, antibiotics in first year, early antibiotic treatment, sleeping position, sleeping place, night awakenings, temperament at 12 months and dummy at 12 months.

In the multivariable analysis, we found that the introduction of fish before 9 months of age had a protective effect on eczema. This is compatible with the findings of Kull et al, ${ }^{31}$ who found that regular fish consumption in the first year of life was

Table 3 Significant (at $p<0.01$ ) risk factors for eczema at 1 year of age in the multivariable analysis: the Infants of Western Sweden Study

\begin{tabular}{llr}
\hline Risk factor & OR (95\% CI) & p Value \\
\hline Maternal eczema & $1.54(1.30$ to 1.84$)$ & $<0.001$ \\
Sibling with eczema & $1.87(1.50$ to 2.33$)$ & $<0.001$ \\
Bird in the home & $0.35(0.17$ to 0.75$)$ & 0.007 \\
Introduction of fish before 9 months & $0.76(0.62$ to 0.94$)$ & 0.009 \\
Cow's milk allergy & $3.64(2.35$ to 5.64$)$ & $<0.001$ \\
\hline
\end{tabular}

associated with a lower risk of eczema at 4 years of age. It has been suggested that a high ratio of omega- 6 to omega- 3 fatty acids, as is common in western diets, could contribute to the pathogenesis of allergic disease. ${ }^{32}$ The fact that fish is rich in omega- 3 fatty acids could partly explain the effects found in this cohort. However, we found no influence of the type of fish ingested (lean/white or fat/oily) in this study, which is compatible with the CAPS study ${ }^{33}$ and recent data from Norway. ${ }^{34}$ The Norwegian study reported beneficial effects on the risk of developing allergic disease if the child ate fish, especially lean fish, but neither the CAPS nor the Norwegian study found that omega-3 fatty acids reduced the risk of allergic disease, including eczema. This makes it somewhat difficult to ascribe the effect to omega-3 fatty acids only. 
Dairy products have also been suggested to have beneficial effects on allergic disease. In a study from the Netherlands, it has been shown that milk and butter consumption reduced the risk of asthma. ${ }^{12}$ However, we were not able to demonstrate any protective effects by dairy products in this study.

The results concerning a possible protective effect on eczema by breast feeding are contradictory. Kull et a ${ }^{35}$ found a protective effect by breast feeding on eczema at 4 years of age and protective effects have also been reported in other studies. ${ }^{36}{ }^{37}$ However, in this study we did not find that breast feeding had any protective effect on the occurrence of eczema. This is in line with the results of Belgian PIPO, the Dutch KOALA and the Australian CAPS studies. ${ }^{9} 1938$

There are also a few studies that claim that prolonged breast feeding can increase the prevalence of eczema. ${ }^{39}$ This may possibly be due to reverse causation, as infants with manifest eczema tend to be breast fed longer than other infants. However, the CAPS study found no significant association between the presence of eczema at 4 weeks and at 3 months and continued breastfeeding beyond those dates. Nor did we find any effects on the prevalence of eczema from parental smoking during or after pregnancy, which is in line with the PIPO study. ${ }^{9}$

In conclusion, we have found that one in five infants in western Sweden have eczema. In a multivariable analysis, we found large effects from heredity and no effect from the duration of breast feeding or the age at which milk or eggs were introduced, while protective effects from introducing fish before 9 months were found.

Funding: The study was supported by the Sahlgrenska Academy at the University of Gothenburg, the Research Foundation of the Swedish Asthma and Allergy Association, the Swedish Foundation for Health Care Sciences and Allergy Research, and the Health \& Medical Care Committee of the Region Västra Götaland.

Competing interests: None.

Ethics approval: This study was approved by the ethics committee at the University of Gothenburg.

\section{REFERENCES}

1. Williams H, Stewart A, Aït-Khaled N, et al. Worldwide variations in the prevalence of symptoms of atopic eczema in the International Study of Asthma and Allergies in Childhood. J Allergy Clin Immunol 1999;103:125-38.

2. Sugiyama $\mathbf{M}$, Arakawa $\mathrm{H}$, Ozawa $\mathrm{K}$, et al. Early-life risk factors for occurrence of atopic dermatitis during the first year. Pediatrics 2007;119:e716-23.

3. Åberg N, Hesselmar B, Åberg B, et al. Increase of asthma, allergic rhinitis and eczema in Swedish schoolchildren between 1979 and 1991. Clin Exp Allergy 1995;25:815-19

4. Asher MI, Montefort S, Björkstén B, et al. Worldwide time trends in the prevalence of symptoms of asthma, allergic rhinoconjunctivitis, and eczema in childhood: ISAAC Phases One and Three repeat multicountry cross-sectional surveys. Lancet 2006;368:733-43.

5. Björksten B, Sepp E, Julge $K$, et al. Allergy development and the intestinal microflora during the first year of life. J Allergy Clin Immunol 2001;108:516-20.

6. Holt PG. Current concepts in pulmonary immunology: regulation of primary and secondary T-cell responses to inhaled antigens. Eur Resp Rev 1996;6:128-35.

7. Hesselmar B, Ảberg N, Aberg B, et al. Does early exposure to cat or dog protect against later allergy development? Clin Exp Allergy 1999:29:611-17.

8. Melén E, Wickman M, Nordvall SL, et al. Influence of early and current environmental exposure factors on sensitization and outcome of asthma in pre-school children. Allergy 2001;56:646-52.

9. Hagendorens MM, Bridts $\mathrm{CH}$, Lauwers $\mathrm{K}$, et al. Perinatal risk factors for sensitization, atopic dermatitis and wheezing during the first year of life (PIPO study). Clin Exp Allergy 2005;35:733-40.

10. Linneberg A, Simonsen JB, Petersen J, et al. Differential effects of risk factors on infant wheeze and atopic dermatitis emphasize a different etiology. J Allergy Clin Immunol 2006;117:184-9.
11. Ludvigsson JF, Moström M, Ludvigsson J, et al. Exclusive breastfeeding and risk of atopic dermatitis in some 8300 infants. Pediatr Allergy Immunol 2005;16:201-8.

12. Wijga $\mathbf{A H}$, Smit HA, Kerkhof M, et al. Association of consumption of products containing milk fat with reduced asthma risk in pre-school children: the PIAMA birth cohort study. Thorax 2003;58:567-72

13. Mihrshahi S, Peat JK, Marks GB, et al. Eighteen-month outcomes of house dust mite avoidance and dietary fatty acid modification in the Childhood Asthma Prevention Study (CAPS). J Allergy Clin Immunol 2003;111:162-8.

14. Alm JS, Swartz J, Björkstén B, et al. An anthroposophic lifestyle and intestinal microflora in infancy. Pediatr Allergy Immunol 2002;13:402-11

15. Cochran WG. Sampling techniques. 3rd edn. New York: Wiley, 1977.

16. Alm B, Möllborg P, Erdes L, et al. SIDS risk factors and factors associated with prone sleeping in Sweden. Arch Dis Child 2006;91:915-19.

17. Alm B, Erdes L, Möllborg P, et al. Neonatal antibiotic treatment is a risk factor for early wheezing. Pediatrics 2008;121:697-702.

18. Norušis M. SPSS 13.0 guide to data analysis. Upper Saddle River, NJ: Prentice Hall, 2005.

19. Snijders BE, Thijs C, Kummeling I, et al. Breastfeeding and infant eczema in the first year of life in the KOALA birth cohort study: a risk period-specific analysis. Pediatrics 2007:119:e137-41.

20. Böhme M, Lannerö E, Wickman M, et al. Atopic dermatitis and concomitant disease patterns in children up to two years of age. Acta Derm Venereol 2002;82:98-103.

21. Socialstyrelsen. Smoking habits among pregnant women and parents to small infants 2002 [Tobaksvanor bland gravida och spädbarnsföräldrar 2002]. Stockholm: Socialstyrelsen (Swedish National Board of Health and Welfare), 2004.

22. Wickman $\mathbf{M}$, Melén $\mathbf{E}$, Berglind $\mathrm{N}$, et al. Strategies for preventing wheezing and asthma in small children. Allergy 2003;58:742-7.

23. Swedish Society of Paediatric Allergology. Prevention - information om möjlighet att minska risken för astma och allergisk sjukdom hos barn under första levnadsåren [Prevention - information about possibilities to decrease the risk of asthma and allergic disease in infants and children during the first years of life]. 2006. Available from: http://www.barnallergisektionen.se/stenciler_nya06/a1_prevention. html (accessed 14 August 2008)

24. Nafstad P, Nystad W, Jaakkola JJ. The use of a feather quilt, childhood asthma and allergic rhinitis: a prospective cohort study. Clin Exp Allergy 2002;32:1150-4.

25. Ponsonby AL, Kemp A, Dwyer $\mathrm{T}$, et al. Feather bedding and house dust mite sensitization and airway disease in childhood. J Clin Epidemiol 2002;55:556-62.

26. Strachan D, Carey IM. Reduced risk of wheezing in children using feather pillows is confirmed. BMJ 1997;314:518.

27. Wadonda-Kabondo N, Sterne JA, Golding J, et al. Association of parental eczema hayfever, and asthma with atopic dermatitis in infancy: birth cohort study. Arch Dis Child 2004;89:917-21

28. Thomsen SF, Ulrik CS, Kyvik KO, et al. Importance of genetic factors in the etiology of atopic dermatitis: a twin study. Allergy Asthma Proc 2007:28:535-9.

29. Palmer CN, Irvine AD, Terron-Kwiatkowski $A$, et al. Common loss-of-function variants of the epidermal barrier protein filaggrin are a major predisposing factor for atopic dermatitis. Nat Genet 2006;38:441-6.

30. Marenholz I, Nickel R, Ruschendorf F, et al. Filaggrin loss-of-function mutations predispose to phenotypes involved in the atopic march. J Allergy Clin Immunol 2006;118:866-71

31. Kull I, Bergström A, Lilja G, et al. Fish consumption during the first year of life and development of allergic diseases during childhood. Allergy 2006:61:1009-15.

32. Fogarty A, Britton J. The role of diet in the aetiology of asthma. Clin Exp Allergy 2000;30:615-27.

33. Marks GB, Mihrshahi S, Kemp AS, et al. Prevention of asthma during the first 5 years of life: a randomized controlled trial. J Allergy Clin Immunol 2006;118:53-61.

34. Øien T, Storrø 0, Johnsen R. Fish and cod liver oil consumption during pregnancy and the first year of life and allergic diseases at 2 years of age. A prospective birth cohort study. Allergy 2008;63(Suppl 88):53.

35. Kull I, Böhme M, Wahlgren CF, et al. Breast-feeding reduces the risk for childhood eczema. J Allergy Clin Immunol 2005;116:657-61.

36. Kramer MS, Chalmers B, Hodnett ED, et al. Promotion of Breastfeeding Intervention Trial (PROBIT): a randomized trial in the Republic of Belarus. JAMA 2001:285:413-20.

37. Laubereau B, Brockow I, Zirngibl A, et al. Effect of breast-feeding on the development of atopic dermatitis during the first 3 years of life--results from the GINIbirth cohort study. J Pediatr 2004;144:602-7.

38. Mihrshahi S, Ampon R, Webb K, et al. The association between infant feeding practices and subsequent atopy among children with a family history of asthma. Clin Exp Allergy 2007;37:671-9.

39. Bergmann RL, Diepgen TL, Kuss 0 , et al. Breastfeeding duration is a risk factor for atopic eczema. Clin Exp Allergy 2002;32:205-9.

40. Pesonen M, Kallio MJ, Ranki A, et al. Prolonged exclusive breastfeeding is associated with increased atopic dermatitis: a prospective follow-up study of unselected healthy newborns from birth to age 20 years. Clin Exp Allergy 2006:36:1011-18. 